\title{
Modification of Phytochemical Production and Antioxidant Activity of Dracocephalum Kotschyi Cells by Exposure to Static Magnetic Field and Magnetite Nanoparticles
}

Marzieh Taghizadeh ( $\square$ Taghizadeh.m66@yahoo.com)

University of Isfahan

Fatemeh Nasibi

Shahid Bahonar University of Kerman

Khosrow Khosrow Manouchehri kalantari

Shahid Bahonar University of Kerman

Mohsen Mohseni-Moghadam

University of Georgia CAGT: University of Georgia Center for Applied Genetic Technologies

\section{Research Article}

Keywords: Antioxidant activity, magnetite nanoparticles, secondary metabolites, suspension culture, static magnetic field

Posted Date: March 2nd, 2021

DOI: https://doi.org/10.21203/rs.3.rs-266160/v1

License: (1) This work is licensed under a Creative Commons Attribution 4.0 International License.

Read Full License 


\section{Abstract}

Dracocephlum kotschyi Boiss is a genus in Lamiaceae family and a medicinal herb native to Iran. The cell suspension cultures were treated by static magnetic field (SMF) and $\mathrm{Fe}_{3} \mathrm{O}_{4}$ magnetite nanoparticles (MNP) to understand the production yield of secondary metabolites. The treatment procedure was done by cultivating the cells either with $100 \mathrm{ppm}$ MNP, SMFs, or simultaneous exposure to both MNP and SMFs. The SMF at $30 \mathrm{mT}$ was uniformly applied to the cells either for 3 or 4 days with a $3 \mathrm{~h}$ per day or a $5 \mathrm{~h}$ per day intervals, respectively. The contents of phenolics and phytochemicals were then examined by high performance liquid chromatography and UV-Vis spectrophotometer. These treatments imposed oxidative stress and induced polyphenol oxidase and phenylalanine ammonia lyase, accompanied by enhanced production of phenolics, anthocyanins, flavonoids, and lignin. The highest membrane embrittlement and elicitation was found upon simultaneous application of the MNPs and SMFs, followed by the MNP and SMFs. The contents of naringin, rosmarinic acid, quercetin, thymol, carvacrol, apigenin, and rutin increased in the intracellular biomass of all treated cells and extracellular culture media. These findings propose the potential of these elicitors in simultaneous production and secretion of these phytochemicals into culture media.

\section{Introduction}

Dracocephalum is a genus in the Lamiaceae family which has been used traditionally in herbal medicine. Dracocephalum kotschyi Boiss is a perennial plant endemic to Iran (known locally as 'Zarrin-giah' or 'Badrandjbooie Denaie) growing in high mountainous areas (Fattahi et al. 2016; Salehi et al. 2015). D. kotschyi was recognized as a source of phytochemicals belonging to terpenoids, phenolics, flavonoids, and alkaloids (Fattahi et al. 2016; Moghaddam et al. 2012). The production of these secondary metabolites can be promoted by biotechnological tools such as plant tissue and cell suspension cultures. These techniques provide a promising bio-production platform for desired natural products and have been applied for increasing the quantity and quality of drugs (Dias et al. 2016; Khvatkov et al. 2015; Yue et al. 2016).

Production of secondary metabolites such as phenolic compounds can be affected by a variety of biotic and abiotic stresses (Ainsworth and Gillespie 2007; Dias et al. 2016). Phenolics serve as a means of counteracting oxidative stresses. These compounds contribute to the transfer of hydrogen to free radicals and the consequent production of a stabilized form of phenoxide radical (Akkol et al. 2008). The phenolics are capable of acting as Fenton reaction inhibitors. Besides, they can directly act as free radical scavengers and reduce oxidative damage, thereby protecting cells against oxidative stress (Heidarabadi et al. 2011).

PAL is an important enzyme in the metabolism of phenolic compounds. It is responsible for catalyzing the first step of the phenyl propanoids pathway, converts phenylalanine to cinnamic acid. Subsequent reactions in the pathway result in the production of a wide variety of phenolic metabolites such as simple phenolics, lignins, flavonoids, and anthocyanins (Dixon and Paira 1995). Moreover, its activity is believed 
to be as a main regulation point between primary and secondary metabolism. The PAL activity depends on some factors, such as genotype, plant development stage, and organ. There are reports on its induction by some environmental stresses (Dixon and Paira 1995; Heidarabadi et al. 2011; Safari et al. 2013; Tahsili et al. 2014). In the oxidative degradation of phenolic compounds, polyphenol oxidase (PPO) catalyzes $\mathrm{O}_{2}$-dependent oxidation of phenolic compounds to highly reactive quinines (Araji et al. 2014). To enhance the production of phenolics, physic-chemical elicitors such as static magnetic field (SMF) and nanoparticle (NP) for plant growth stimulation and phytochemical production have been widely applied as environmentally benign techniques in recent years (Aladjadjiyan 2010). The response of plant cells to magnetic field exposure was different depending on plant species, magnetic field intensity, and exposure time. As an example, the PPO activity and phenolic contents were strongly induced in hazel cell suspension cultures upon treatment by static magnetic field (SMF) as well as by SMF combined with salicylic acid (Rezaei et al. 2010). Shang et al. (2004) reported that taxol production was improved in Taxuschinensis cell suspension cultures by the SMF elicitation.

The influence of magnetic field (MF) on living organisms is through induction of oxidative stress and increase in the concentration, activity, and lifetime of free radicals. It also affects ionic currents in the cell membrane and other cellular transport processes, increases cell membrane permeability, and alters the electromagnetic properties of cell biological molecules (Çelik et al. 2009; Galland and Pazur 2005; Nagy and Fischl 2004; Payez et al. 2013; Radhakrishnan et al. 2012b; Sahebjamei et al. 2007; Tenforde 1996). Alterations of the enzymatic activities, such as catalase (CAT), superoxide dismutase (SOD), and peroxidase, by external SMF suggest their possible implication in magnetoreception. However, the exact mechanism of SMF on living organisms is still unclear and continuous research in this regard is of high demand (Payez et al. 2013; Sahebjamei et al. 2007).

The NPs have been applied for agricultural and horticultural purposes (Dimkpa et al. 2012). The positive or negative effects of metal nanoparticles on higher plants strongly depend on plant species and the physic-chemical properties of NPs. There are several reports on the enhanced production of reactive oxygen species (ROS) and oxidative stress during the application of NPs to plant culture media (Dhoke et al. 2013; Lee et al. 2012; Li et al. 2013; Ma et al. 2010; Wang et al. 2006). Li et al. (2013) demonstrated that watermelon treatment with $\mathrm{Fe}_{3} \mathrm{O}_{4}$ NPs caused physiological changes in the activities of CAT, PPO, SOD, and ferric reductase as well as in the contents of chlorophylls and malonyldialdehyde (MDA). The levels of total phenolicsin plants and the activities of antioxidant enzymes SOD and CAT were also increased upon treatment with chitosan NPs (Chandra et al. 2015). In Taxus chinensis cell suspension culture, AgNPs (5 ppm) significantly increased taxol production in comparison to the control cells (Jamshidi et al. 2016).

In the present research, two SMFs as physical and $\mathrm{Fe}_{3} \mathrm{O}_{4}$ magnetite NPs as chemical elicitors were applied separately and simultaneously to the suspension-cultured $D$. kotschyi cells. This study was aimed to find out the underlying physiological responses upon these treatments as well as the quantity and quality of phytochemicals. This understanding could lead us to an effective strategy towards improved yield of beneficial secondary metabolites from undifferentiated plant cells. 


\section{Materials And Methods \\ 2.1. Cell Growth Conditions}

$D$. kotschyi seeds were collected from wild-growing plant populations from Fereydonshahr mountainous area located $2700 \mathrm{~m}$ above sea level in Isfahan, Iran. For callus induction, the explants of $D$. kotschyi were obtained from in vitro grown plants on the Murashige and Skoog (MS) medium. Plant growth regulators of 1-naphthaleneacetic acid (NAA) (1 $\left.\mathrm{mg} \mathrm{L}^{-1}\right)$ and 6-benzylaminopurine (BAP) $\left(6 \mathrm{mgL}^{-1}\right)$ were added to the MS medium, which was supplemented with $30 \mathrm{~g} \mathrm{~L}^{-1}$ sucrose and $8 \mathrm{~g} \mathrm{~L}^{-1}$ agar, at $24 \pm 2{ }^{\circ} \mathrm{C}$ under dark condition. The suspension cultures were established from calli of $D$. kotschyi cells. The suspensions were grown in a modified B5 medium (Gamborg et al. 1976) containing $2 \%$ sucrose with NAA (1 mg L-1) and BAP $\left(2.5 \mathrm{mg} \mathrm{L}^{-1}\right)$ at $24{ }^{\circ} \mathrm{C}$ in darkness on an orbital shaker at $120 \mathrm{rpm}$ and were sub-cultured every 10 days at their logarithmic growth phase.

\subsection{Elicitation Treatments with Static Magnetic Field}

The $D$. kotcshyi cells were exposed to uniform SMF $(30 \mathrm{mT})$ by a MF generator device designed and built in-house. The electrical power of the system was provided by a 220-V AC power supply equipped with variable transformer as well as a single-phase and full-wave rectifier (Model RD 4025, Rahavand, Tehran, Iran). The maximum power and flowing current were measured $1 \mathrm{~kW}$ and $50 \mathrm{~A} \mathrm{DC}$, respectively. This system was clearly described by Shokrollahi et al. (2018) and did not discuss herein for brevity.

For elicitation purposes, the SMF intensity was commonly ranged from 10 to $50 \mathrm{mT}$ (Wang et al. 2008) and the field intensity of $30 \mathrm{mT}$ was frequently applied to plant cell models (Haghighat et al. 2014; Sahebjamei et al. 2007; Shokrollahi et al. 2018). The elicitation period was chosen based on some preliminary experimental works and literature review (Payez et al. 2013; Sahebjamei et al. 2007; Shokrollahi et al. 2018). The elicitation group was put in the SMF producing system and the control groups was placed far away from the MF generating device and any other laboratory instruments, e.g. NMR, to avoid unwanted exposure to MF other than the local earth MF of $60 \mu \mathrm{T}$, as determined by the Geophysics Institute, University of Tehran (Tehran, Iran). The treated cells were exposed to uniform and homogenous $30 \mathrm{mT}$ SMF in their exponential growth phase (from day 7 to 10 after sub-cultures) for 3 days at $3 \mathrm{~h}$ per day interval (so called SMF1) and for 4 days at a $5 \mathrm{~h}$ per day interval (so called SMF2). The elicitation duration was chosen slightly less than the previous works because there is high possibility of cellular damage upon simultaneous application of SMFs and MNPs. The presence of a pulsation frequency of $50 \mathrm{~Hz}$ with a range of voltage variation about $\pm 1 \mathrm{~V}$ in the current from rectifier into the SMF generating apparatus was detected possibly due to the shortcoming of the applied single-phase and fullwave rectifier, providing a ripple voltage of $\sim 5 \%$. This small ripple voltage confirms the homogeneity of the generated magnetic field, the measurement by a Teslameter (13610.93, PHYWE, Gottingen, Germany) approved its accuracy and uniformity. A precise indication of the simulated field levels in Computer Simulation Technology was presented as the test of homogeneity of SMF in previous paper (Payez et al. 2013). 


\subsection{Characterization and Application of Magnetite Nanoparticles}

The MNPs were supplied from the US Research Nanomaterial (Houston, TX). The diameters of MNPs were ranged from $10-20 \mathrm{~nm}$ with $99.99 \%$ purity, according to the manufacturer protocol. The nanoparticles were dispersed by suspension in $0.05 \%$ dimethyl sulfoxide (DMSO) prepared with deionized water (Pandya and Singh, 2015). The DMSO was selected because it is a significant polar aprotic solvent dissolving both polar and nonpolar compounds. Moreover, it is miscible in many organic solvents as well as in water. The MNP in DMSO was then kept in water in an ultrasonic bath for $25 \mathrm{~min}$. Seven days after cell subculture, a $100 \mathrm{ppm}$ MNP was added to the liquid culture media of the cells. Two control groups were used in the present research including the cells grown in the culture medium with no MNP and the ones grown in the culture medium with $0.05 \%$ DMSO without MNP in darkness. The concentration of MNP (100 ppm) was selected based on some preliminary experimental works and literature studies (Jalali et al. 2017; Li et al. 2016; Zadeh et al. 2019).

\subsection{Application of SMF Combined with Magnetite Nanoparticles}

The cells in their exponential growth phase (7 day after cell subculture) were treated with 100 ppm MNPs. These samples were then divided into two groups: One group were placed in the SMF generating apparatus under $30 \mathrm{mT}$ SMF for 3 days at $3 \mathrm{~h}$ per day interval (SMF1 + MNP) and the second group was exposed to the same SMF for 4 days at $5 \mathrm{~h}$ per day intervals (SMF2 + MNP), from day 7 to 10 after subculture. The control cells consists of two groups, the first group grown in the culture medium without MNP, and the second one grown in the culture medium with $0.05 \%$ DMSO, then were kept far from the SMF producing system.

The suspension cultures were harvested at the end of all elicitations by filtration using a Buchner funnel with a nylon mesh under vacuum. The harvested biomass was frozen in liquid $\mathrm{N}_{2}$ and kept at $-80^{\circ} \mathrm{C}$ for further phytochemical and physiological analysis.

\subsection{Contents of Total Phenolics, Flavonoids, Flavonols, and Anthocyanins}

Total phenolic contents were determined using the Folin-Ciocalteau method as discussed in Chua et al. (2011). A $500 \mu \mathrm{L}$ methanolic extract of fresh cell mass $(200 \mathrm{mg})$ was used for determination of phenolic content by measuring absorbance at $765 \mathrm{~nm}$ using a UV/Vis spectrophotometer (Cintra6, GBC, Dandenong, Australia). Total flavonoid and flavonol contents were estimated according to the protocol of Miliauskas and Venskutonis (2004). The methanolic extract of $200 \mathrm{mg}$ fresh cell mass was used for UVVis spectrophotometer determination of total flavonoids and flavonols at 445 and $415 \mathrm{~nm}$, respectively. The contents of total flavonoids and flavonols were expressed as mg rutin equivalents per gram of fresh mass (mg RU g ${ }^{-1} \mathrm{FW}$ ). 
To measure anthocyanin contents, the acidic methanol (99/1, methanol/acetic acid) extract of a $200 \mathrm{mg}$ fresh cell mass was used according to the protocol of (Hara et al. 2003). The total anthocyanin contents was determined by measuring the absorbance at $511 \mathrm{~nm}$ using the spectrophotometer and quantified based on the extinction coefficient of $33,000 \mathrm{M}^{-1} \mathrm{~cm}^{-1}$.

\subsection{Lignin Content Assay}

The dried powdered cell walls of each sample $(6 \mathrm{mg})$ were extracted with $25 \mathrm{vol} . \%$ acetyl bromide (in glacial acetic acid) and $100 \mu \mathrm{L}$ of $70 \% \mathrm{HClO}_{4}$, according to Ghanati et al. (2005). The lignin content was determined by measuring spectrophotometeric absorbance at $280 \mathrm{~nm}$ and quantified using the specific absorption coefficient value of $20.0 \mathrm{~L} \mathrm{~g}^{-1} \mathrm{~cm}^{-1}$ (liyama et al. 1990).

\subsection{Activity Assay of Phenylalanine Ammonia Lyase and Polyphenol Oxidase}

The phenylalanine ammonia lyase (PAL) activity was determined by the method of Ochoa-Alejo and Gómez-Peralta (1993) through measurement of cinnamic acid production by the spectrophotometer at $290 \mathrm{~nm}$. To this end, a $200 \mathrm{mg}$ cell mass of each sample was extracted by $\beta$-mercaptoethanol $(15 \mathrm{mM})$ in Tris- $\mathrm{HCl}(\mathrm{pH} 8.2,100 \mathrm{mM})$ buffer. One unit of PAL activity was expressed as amounts of cinnamic acid produced within one hour per $\mathrm{mg}$ of protein.

The PPO activity was assayed according to Kahn et al. (1975). A $200 \mathrm{mg}$ fresh cell mass was used for enzyme extraction by $3 \mathrm{~mL}$ of $20 \mathrm{mM}$ sodium phosphate buffer ( $\mathrm{pH} 6.8$ ) containing $0.1 \mathrm{mM}$ EDTA.

\subsection{Measurement of Phytochemical Products}

Phytochemical products of the cells and culture media were extracted according to Barreca et al. (2016) with slight modifications. For this purpose, the lyophilized culture medium with no cells $(15 \mathrm{~mL})$ and the dry cell mass $(100 \mathrm{mg}$ ) was homogenized by $2 \mathrm{~mL}$ acidic methanol (99 methanol / 1 acetic acid), extracted with ultrasonic for $20 \mathrm{~min}$, and incubated overnight at room temperature. The homogenate was centrifuged at 10,000 rpm for $20 \mathrm{~min}$. The supernatant was gathered and allowed to evaporate at room temperature. The residues were dissolved in $300 \mu \mathrm{L}$ methanol and filtered ( $0.22 \mu \mathrm{m}$ pore size) into clean vials.

For quantitative and qualitative determination of phytochemical products in methanol, a High Performance Liquid Chromatography (HPLC) program equipped with a UV-Vis photodiode-array detector (DAD-HPLC Waters e 2695, alliance, Milford, MA, 2489 UV- Vis detector) was used. For the analysis of phytochemical products, a $20 \mu \mathrm{L}$ aliquot of the filtered sample was injected into the HPLC. The chromatographic separation was obtained by a C18 column (Perfectsil Target ODS-3 (5 mm), 2504.6 mm; MZ Analysentechnik, Mainz, Germany) with solvent A (water / acetic acid, 97/3, v/v) and solvent B (methanol) under the following gradient conditions: 0-3 min, 0\% B; 3-9 min, 3\% B; 9-24 min, 12\% B, 24$33 \mathrm{~min}, 20 \%$ B, 33-43 min, 30\% B; 43-63 min, 50\% B; 63-66 min, 50\% B; 66-81 min, 60\% B; 81-86 min, $0 \%, \mathrm{~B}$ and equilibrated $4 \mathrm{~min}$ for a total run time of $90 \mathrm{~min}$. The flow rate was $1.0 \mathrm{~mL} \mathrm{~min}{ }^{-1}$, injection 
volume was $20 \mu \mathrm{L}$, and the column thermostat was held constant at $26^{\circ} \mathrm{C}$. The UV spectra of phytochemical products were recorded at 280 and $325 \mathrm{~nm}$ (Barreca et al. 2016). To confirm the peak identity, their retention times and absorption spectra were compared with those of pure (>99\%) standards of apigenin, naringin, rosmarinic acid, rutin, quercetin, thymol, and carvacrol.

\subsection{Hydrogen Peroxide Contents and Lipid Peroxidation Assay}

The peroxides were first extracted from the fresh biomass $(200 \mathrm{mg})$ by grinding to homogenization in 5 $\mathrm{mL}$ of $0.1 \%(\mathrm{v} / \mathrm{v})$ trichloroacetic acid using a pestle and mortar. The homogenate was centrifuged at $10000 \mathrm{rpm}$ for $20 \mathrm{~min}$, then $0.5 \mathrm{~mL}$ of supernatant was mixed with $500 \mu \mathrm{L}$ of $10 \mathrm{mM}$ potassium phosphate buffer $(\mathrm{pH} 7)$ and $1 \mathrm{~mL}$ of $1 \mathrm{M} \mathrm{KI}$. Absorbance of the mixture solution was read at $390 \mathrm{~nm}$ by a double beam spectrophotometer (Jamshidi et al. 2016). To determine the amount of lipid peroxidation, the MDA of the cells were measured as the product of peroxidation of membrane lipids, according to the method of Heath and Packer (1968).

\subsection{Data Presentation and Statistical Analyses}

Statistical analyses were conducted using Statistical Package for the Social Sciences (SPSS) version No 19.0, Chicago, IL, USA. The experiments followed a completely randomized design and the values were presented as means \pm SE (standard error). All the experiments and observations were replicated three times each with at least three samples. The significant differences between treatments were evaluated using the Duncan's test at $p \leq 0.05$.

\section{Results}

\subsection{Peroxide Contents and Lipid Peroxidation}

The contents of peroxide and MDA increased remarkably in all elicited cells compared to those of control (Fig. 1A). The highest increases of $52 \%$ and $35 \%$ in the peroxide and MDA were observed upon treatment with SMF1 + MNP and SMF2 + MNP compared to that of the control, respectively. The cells treated with the magnetic field in combination with the nanoparticles (SMF1 + MNP and SMF2 + MNP) were of significant differences in the peroxide and MDA levels; while there were no significant differences between the levels of lipid peroxidation in the cells treated with the SMF1 and SMF2 (Fig. 1A). However, the peroxide contents of the cells treated with SMF2 was significantly higher than those treated with SMF1. The MNP application caused a significant increase of $12 \%$ in the MDA compared to that of control; while two control groups were of no significant differences in the peroxidation levels.

\subsection{Total Phenolic, Flavonoids, Flavonol, Anthocyanin, and Lignin Contents}


The bioaccumulation of total phenolics in the cells undergone the SMF and MNP treatments significantly increased compared to that of control (Fig. 1B). The highest effect of elicitation on total phenolic contents was observed under SMF2 + MNP treatment, amounting to $7.7 \mathrm{mg}$ gallic acid $\mathrm{g}^{-1} \mathrm{FW}$ that is 2.1 times higher than that of control (Fig. 1B). The MNP was of higher elicitation effect on total phenolics than treatment with the SMF. The lowest elicitation was observed upon treatment of the cells with the SMF1 (4.64 $\left.\mathrm{mg} \mathrm{g}^{-1} \mathrm{FW}\right)$.

The contents of total flavonoids and flavonols were increased in the treated cells compared with those of control (Fig. 1C). The greatest amount of total flavonoids were measured $312.76 \mu \mathrm{g} \mathrm{Rutin}^{-1} \mathrm{FW}$ and $310.93 \mu \mathrm{g}$ Rutin $\mathrm{g}^{-1} \mathrm{FW}$ in the cells treated with SMF2 + MNPs and SMF1 + MNPs, respectively. It was increased by about 1.25 fold compared to that of control. There were no significant differences between the levels of total flavonoids in the cells treated with the MNPs, SMF1 and SMF2 (Fig. 1C). The results indicated that the flavonol contents increased significantly from $101.21 \mu \mathrm{g}$ Rutin $\mathrm{g}^{-1} \mathrm{FW}$ in the control cells to $144.76 \mu$ gutin $\mathrm{g}^{-1} \mathrm{FW}$ in the cells treated with the SMF1 + MNP (Fig. 1C). The increase in the flavonol contents was about 1.43 fold in comparison to that of the control samples. There were no significant differences between the levels of flavonol in the cells treated with the SMF1 and SMF2 + MNP. It was found that the flavonol contents were decreased in the cells treated with SMF2 + MNP compared to those treated with MNP, SMF2 and SMF1 + MNPs.

Anthocyanin content, as a subgroup of flavonoids, significantly increased in the cells treated with SMF2, SMF1 + MNP, and SMF2 + MNP (Fig. 1C). The highest content of anthocyanins ( $29.57 \mathrm{nmolg}^{-1} \mathrm{FW}$ ) was measured in the cells treated with SMF2 + MNP. This increase is about 1.64 times higher than that of control cells. Other elicitors showed no significant difference regarding the contents of anthocyanins (Fig. 1C).

The lignin content showed a significant increase in all treatments compared to those of control (Fig. 1D). The highest amount of lignin was observed in the SMF2 + MNP treatment ( $19.04 \%$ of cell wall DW) that was three times higher than that of the control cells ( $6.32 \%$ of cell wall DW). The next highest content of lignin was measured in the cells treated with MNP and SMF1 + MNP. It was found that the MNP treatment combined with the SMF1 has no significant elicitation effect than the sole MNP treatment. Among the physicochemical treatments, the SMF1 was of the lowest elicitation effect on the cells that is nearly identical to that of control (Fig. 1D). Furthermore, the MNP was of higher elicitation effect than treatment with the SMF.

\subsection{Enzymatic Activities}

The activity of PAL enzyme increased significantly in all treated cells (Fig. 2). The highest PAL activity was observed in the cells treated with SMF2 + MNP, amounting to $1539.49 \mu \mathrm{g}$ Cinamicacid $\mathrm{mg}^{-1} \mathrm{~h}^{-1}$. This elicitor resulted in 2.06 fold higher PAL activity than that of the control cells (Fig. 2). The cells treated with MNPs were of higher PAL activity than the ones treated with the SMFs. The combination of two 
treatments more significantly affected the cells' enzymatic activity than the separate application of either one of treatments.

Similarly, the highest PPO activity was observed upon treatment with the SMF2 + MNP (Fig. 2). It was measured 16.55 Abs $410 \mathrm{mg}^{-1} \mathrm{~min}^{-1}$ under the control conditions and 44.37 and $41.58 \mathrm{Abs} 410 \mathrm{mg}^{-1}$ $\min ^{-1}$ upon the SMF2 + MNP and SMF2 elicitations, respectively. However, the SMF2 was of higher elicitation effect than treatment with the MNPs. The highest increase in the PPO activity was 2.54 fold and 2.39 fold higher than that of control for the cells treated with SMF2 + MNP and SMF2, respectively (Fig. 2). Therefore, all treatments were significantly enhanced the PPO and PAL activities under elicitation conditions in comparison to control cells.

\subsection{The Contents of Phytochemical Products}

This study showed that the contents of phytochemical products such as rutin, apigenin, naringin, thymol, quercetin, carvacrol, and rosmarinic acid in all treatments remarkably increased compared with those of the control cells (Table 1). The highest amounts of rosmarinic acid and carvacrol were observed in the cells treated with SMF1 + MNP and SMF2 + MNP, respectively. The cells treated with SMF2 and SMF2 + MNP caused the highest value of rutin. The apigenin, quercetin, and thymul measured highest in the cells treated with SMF1. Furthermore, the greatest amount of naringin was observed in the cells treated with the MNP (Table 1). As the contents of phytochemical compounds increased in the cells under all treatments, the amounts of these compounds were considerably increased in all treated culture media in comparison with the control culture media. The SMF1 induced higher contents of all phytochemical products except rutin than the SMF2 treatment (Table 1). It was of higher elicitation effect than the MNP as well. However, these two SMF treatments did not significantly different in the excreted phytochemical products into the culture media (Table 2). Except for rutin and quercetin, the extracellular contents of the cells treated with SMF2 were 2.5 and 3.0 times higher than those treated with the SMF1, respectively. The combined application of the SMF2 + MNP resulted in the highest and the SMF1 led to the lowest secretion of the phytochemicals (Table 2). 
Table 1

Effects of MNP (100 ppm), static magnetic field $(30 \mathrm{mT})$, and their combination on the amount of phytochemical products ( $\mu \mathrm{g} \mathrm{g}{ }^{-1} \mathrm{DW}$ ) in the $D$. kotschyi cells measured by HPLC. MNP: $\mathrm{Fe}_{3} \mathrm{O}_{4}$ magnetic nanoparticles, SMF1: Static magnetic field for 3 days, 3h a day, SMF2: Static magnetic field for 4 days, 5 $\mathrm{h}$ a day, MNP + SMF1: Static magnetic field for 3 days, $3 \mathrm{~h}$ a day with $\mathrm{Fe}_{3} \mathrm{O}_{4} \mathrm{MNP}$, MNP + SMF2: Static magnetic field for 4 days, $5 \mathrm{~h}$ a day with $\mathrm{Fe}_{3} \mathrm{O}_{4} \mathrm{MNP}$.

\begin{tabular}{|c|c|c|c|c|c|c|c|}
\hline \multicolumn{8}{|c|}{ Phytochemical products ( $\mu \mathrm{g} \mathrm{g}^{-1} \mathrm{DW}$ ) } \\
\hline Treatments & Naringin & Rutin & Quercetin & Apigenin & $\begin{array}{l}\text { Rosmarinic } \\
\text { acid }\end{array}$ & Thymol & Carvacrol \\
\hline Control & $\begin{array}{l}8.45 \pm \\
4.3^{d}\end{array}$ & $\begin{array}{l}1.63 \pm \\
1.88^{\mathrm{e}}\end{array}$ & $\begin{array}{l}22.38 \pm \\
3.6^{c}\end{array}$ & $\begin{array}{l}23.33 \pm \\
2.11^{f}\end{array}$ & $9.76 \pm 1.8^{\mathrm{d}}$ & $\begin{array}{l}5.17 \pm \\
0.97^{c}\end{array}$ & ND \\
\hline MNP & $\begin{array}{l}73.25 \pm \\
5.6^{\mathrm{a}}\end{array}$ & $\begin{array}{l}5.41 \pm \\
50.78^{\mathrm{cd}}\end{array}$ & $\begin{array}{l}86 \pm \\
1.02^{b}\end{array}$ & $\begin{array}{l}103.6 \pm \\
4.2^{c}\end{array}$ & $\begin{array}{l}17.53 \pm \\
5.8^{c}\end{array}$ & $\begin{array}{l}12.34 \pm \\
1.2^{\mathrm{ab}}\end{array}$ & $\begin{array}{l}2.29 \pm \\
0.93^{b c}\end{array}$ \\
\hline SMF1 & $\begin{array}{l}23.72 \pm \\
1.4^{\mathrm{b}}\end{array}$ & $\begin{array}{l}8.062 \pm \\
0.41^{c}\end{array}$ & $\begin{array}{l}105 \pm \\
1.12^{\mathrm{a}}\end{array}$ & $\begin{array}{l}143.3 \pm \\
8.16^{\mathrm{a}}\end{array}$ & $\begin{array}{l}16.23 \pm \\
9.89^{c}\end{array}$ & $\begin{array}{l}13.98 \pm \\
2.11^{\mathrm{a}}\end{array}$ & $\begin{array}{l}2.53 \pm \\
0.72^{b}\end{array}$ \\
\hline SMF2 & $\begin{array}{l}16.53 \pm \\
0.92^{\mathrm{c}}\end{array}$ & $\begin{array}{l}20.69 \pm \\
0.85^{a}\end{array}$ & $\begin{array}{l}12.35 \pm \\
2.09^{f}\end{array}$ & $\begin{array}{l}121.6 \pm \\
7.3^{b}\end{array}$ & $\begin{array}{l}8.92 \pm \\
2.25^{d}\end{array}$ & $\begin{array}{l}11.71 \pm \\
0.5^{\mathrm{ab}}\end{array}$ & $\begin{array}{l}2.68 \pm \\
1.57^{b}\end{array}$ \\
\hline $\begin{array}{l}\text { MNP+ } \\
\text { SMF1 }\end{array}$ & $\begin{array}{l}15.05 \pm \\
1.48^{\mathrm{c}}\end{array}$ & $\begin{array}{l}18.42 \pm \\
1.23^{\mathrm{ab}}\end{array}$ & $\begin{array}{l}20.78 \pm \\
0.91^{\text {cd }}\end{array}$ & $\begin{array}{l}43.01 \pm \\
2.52^{d}\end{array}$ & $\begin{array}{l}53.57 \pm \\
17.83^{a}\end{array}$ & $\begin{array}{l}9.11 \pm \\
2.04^{b}\end{array}$ & $\begin{array}{l}2.03 \pm \\
1.1^{c}\end{array}$ \\
\hline $\begin{array}{l}\text { MNP + } \\
\text { SMF2 }\end{array}$ & $\begin{array}{l}15.21 \pm \\
0.23^{\mathrm{C}}\end{array}$ & $\begin{array}{l}20.98 \pm \\
1.54^{\mathrm{a}}\end{array}$ & $\begin{array}{l}16.36 \pm \\
0.82^{d}\end{array}$ & $\begin{array}{l}31.16 \pm \\
4.11^{\mathrm{e}}\end{array}$ & $\begin{array}{l}21.62 \pm \\
6.01^{b}\end{array}$ & $\begin{array}{l}14.9 \pm \\
1.37^{a}\end{array}$ & $\begin{array}{l}3.25 \pm \\
2.1^{\mathrm{a}}\end{array}$ \\
\hline
\end{tabular}


Table 2

Effects of MNP (100 ppm), static magnetic field (30 mT), and their combination on the amount of phytochemical products ( $\mu \mathrm{g} \mathrm{mL}^{-1}$ culture media) in the culture media of $D$. kotschyi cells measured by HPLC. MNP: $\mathrm{Fe}_{3} \mathrm{O}_{4}$ magnetic nanoparticles, SMF1: Static magnetic field for 3 days, $3 \mathrm{~h}$ a day, SMF2: Static magnetic field for 4 days, $5 \mathrm{~h}$ a day, MNP + SMF1: Static magnetic field for 3 days, $3 \mathrm{~h}$ a day with $\mathrm{Fe}_{3} \mathrm{O}_{4} \mathrm{MNP}, \mathrm{MNP}+\mathrm{SMF2}$ : Static magnetic field for 4 days, $5 \mathrm{~h}$ a day with $\mathrm{Fe}_{3} \mathrm{O}_{4}$ MNP, ND: Not detected.

\section{Phytochemical products $\left(\mu \mathrm{g} \mathrm{mL}^{-1}\right.$ culture media)}

\begin{tabular}{|llllllll|}
\hline Treatments & Naringin & Rutin & Quercetin & Apigenin & $\begin{array}{l}\text { Rosmarinic } \\
\text { acid }\end{array}$ & Thymol & Carvacrol \\
Control & ND & $1.6 \pm$ & ND & ND & ND & ND & ND \\
MNP & $2.34 \pm$ & $4.5 \pm$ & $2.56 \pm$ & $3.53 \pm$ & $17.54 \pm$ & $2.98 \pm$ & ND \\
& $0.73^{\mathrm{c}}$ & $1.01^{\mathrm{d}}$ & $0.18^{\mathrm{d}}$ & $0.4^{\mathrm{b}}$ & $1.25^{\mathrm{c}}$ & $0.41^{\mathrm{b}}$ & \\
\hline SMF1 & $2.98 \pm$ & $2.58 \pm$ & $1.9 \pm$ & $2.7 \pm$ & $4.12 \pm 0.88^{\mathrm{d}}$ & $2.68 \pm$ & ND \\
& $0.7^{\mathrm{b}}$ & $1.45^{\mathrm{e}}$ & $3.46^{\mathrm{e}}$ & $1.02^{\mathrm{c}}$ & & $0.15^{\mathrm{b}}$ & \\
SMF2 & $3.02 \pm$ & $6.46 \pm$ & $5.79 \pm$ & $2.59 \pm$ & $4.53 \pm 3^{\mathrm{d}}$ & $2.57 \pm$ & $\mathrm{ND}$ \\
& $0.3^{\mathrm{b}}$ & $1.3^{\mathrm{c}}$ & $1.25^{\mathrm{b}}$ & $1.06^{\mathrm{c}}$ & & $0.13^{\mathrm{b}}$ & \\
MNP+ & $2.68 \pm$ & $9.76 \pm$ & $5.03 \pm$ & $2.77 \pm$ & $27.75 \pm 5.1^{\mathrm{b}}$ & $3.04 \pm$ & ND \\
SMF1 & $0.96^{\mathrm{bc}}$ & $0.53^{\mathrm{b}}$ & $0.99^{\mathrm{c}}$ & $0.05^{\mathrm{c}}$ & & $0.13^{\mathrm{b}}$ & \\
\hline MNP + & $15.26 \pm$ & $19.76 \pm$ & $7.74 \pm$ & $4.76 \pm$ & $84.97 \pm$ & $5.27 \pm$ & ND \\
SMF2 & $2.01^{\mathrm{a}}$ & $4.37^{\mathrm{a}}$ & $1.2^{\mathrm{a}}$ & $0.07^{\mathrm{a}}$ & $9.98^{\mathrm{a}}$ & $0.23^{\mathrm{a}}$ & \\
\hline
\end{tabular}

Data were shown in mean \pm SE. Different lowercase letters show a significant difference at $P \leq 0.05$.

\section{Discussion}

\subsection{Effect of the SMFs and MNPs on the Antioxidant Defense Mechanism}

This study analyses the production of phytochemicals in suspension-cultured $D$. kotschyi cells upon exposure to SMF and MNP. The cell suspension cultures of higher plants were suggested as useful models for studying the regulation and production of secondary metabolites (Tahsili et al. 2014).

The SMFs alter the electrical behaviors and permeability of cellular membranes through magnetic induction (Wang et al. 2008). The magnetic field affects on the orientation of the membrane phospholipids and then causes deformation of membrane channels (Radhakrishnan et al. 2012a). The SMFs influence the spins of cellular paramagnetic molecules and interrupt the associated chemical reactions as well. All these occurrences accompanied by oxidative stress and accumulation of peroxide contents (Fig. 1A). The response of plant cells to SMF exposure is dependent on many factors such as the plant species, SMF intensity, and exposure period (Çelik et al. 2009; Maffei 2014; Payez et al. 2013). 
The higher peroxide contents of the cells upon exposure to SMF2 than SMF1 can be attributed to higher exposure period.

The treatment of the plant cells with MNP supply the cells with excess iron nutrients (Zia-ur-Rehman 2018). As a consequence it could stimulate Fenton reaction and generates hydrogen peroxide, hydroxyl radicals, and the superoxide anion. All these molecules result in oxidative stress ( $\mathrm{Li}$ et al. 2013). The attachment of MNP to the cell membranes can disturb permeability due to adverse effects on membrane transport processes resulting in the generation of reactive oxygen species (Jalali et al. 2017; Jamshidi et al. 2016), a possible reason for higher lipid peroxidation than the SMFs (Fig. 1A). However, the lower peroxide contents of the cells treated with the MNPs than the SMFs might be related to the supplementation of the plants with iron oxide NPs that stimulates the activity of antioxidant enzymes and scavenges reactive oxygen species (Zia-ur-Rehman et al. 2018).

Iron is a ferromagnetic element and act as a magneto-receptor in cells under magnetic field treatment (Rajabbeigi et al. 2013). These direct effects of MNPs on cellular function and structures could be a possible reason for imposing higher elicitation than the SMFs (Fig. 1A, 1B, and 1D). The MNPs combined with magnetic fields led to higher ROS accumulation in the cells than the separate application of either one of elicitors (Ghanati et al. 2007). lons such as iron in the cell have the ability to absorb magnetic energy; therefore the SMF cause the torque generation of magnetite nanoparticles (Aladjadjiyan 2010) and migration into the cells and culture media. Accordingly, the MNP may get new feature under magnetic field and impact more the cell function and induce more oxidative stress. It is a possible reason for higher MDA contents of the cells treated simultaneously with both magnetic field and MNPs (Fig. 1A). The cells treated with SMF2 + MNP are also exposed more time to MNPs than the ones treated with SMF1 + MNP that is one other possible reason for their higher MDA contents. The MDA is a cytotoxic product of lipid peroxidation and an indicator of free-radical accumulation (Coşkun et al. 2009; Rajabbeigi et al. 2013). The oxidative stress was induced possibly due to disruption of the membrane integrity and enhanced membrane permeability (Abdolmaleki et al. 2007). Accordingly, the cells were not able to prevent peroxidation of their membrane lipids (Rajabbeigi et al. 2013). These observations suggest that antioxidant system is significantly stimulated by increasing the duration of exposure to magnetic field and MNPs. The present findings also suggest that the SMF amplified the effect of MNP on cell physiological responses. The contents of total phenolics, flavonoids, anthocyanins, and lignin as well as the activities of PAL and PPO under combined elicitation of SMF and MNP were significantly higher than those of cells treated with either MNP or SMF alone.

The highest to lowest increase in the MDA contents of the cells was observed respectively upon treatments with SMFs + MNP, MNPs, and SMFs that is consistent with the enhancements in PAL activities (Fig. 2), total phenolics (Fig. 1B), and lignin contents (Fig. 1D). The peroxides are signaling molecules activating defensive pathways under stress conditions (Rezaei et al. 2010). To counteract the oxidative stress damages, the plant cells developed various enzymatic and non-enzymatic antioxidant defense mechanisms. The PAL is considered as an important enzyme in the phenylpropanoid pathway and involved with the plant cells defense response to ROS. The PAL activity was also considered as an 
efficient marker for identifying the intensity of environmental stresses in plant species (Golkar et al. 2019b). The phenolics are secondary metabolites with protective effects against oxidative stress (Manquián-Cerda et al. 2016; Maqsood et al. 2014). Various studies have highlighted the strong relationship between plant secondary metabolism and defense responses (Çelik et al. 2009; Maffei 2014; Sahebjamei et al. 2007; Tahsili et al. 2014). The increase in the phenolics of the cells under different elicitations can also be attributed to their role in the stimulation of enzymatic activities and the expression of the genes contributing to the shikimate pathway (Golkar and Taghizadeh 2018). Safari et al. (2013) demonstrated that the phenolic content of hazel cells increased when the cells were exposed to ultrasound treatment. Also, it has been reported that in Taxus cell culture, the increase in the PAL activity caused by Taxol production after exposure to magnetic fields (Shang et al. 2004). Jamshidi et al. (2016) showed an increase in PAL activity and phenolic contents during the AgNPs treatment of hazel cell suspension culture. Total polyphenol increases the antioxidant potential in plants. These compounds might act as iron chelators, Fenton reaction inhibitor, or directly remove free radicals and decrease the oxidative damage (Ghanati et al. 2007). In fact, the higher phenolic compounds may protect plant cells from the SMF- and MNP-induced stresses and it will interfere with the signaling cascades involved in plant responses. In agreement with our findings, the treatment of suspension-cultured plant cells with magnetic fields and MNPs led to oxidative stress and accompanied by a change in the activities of scavenging enzymes such as catalase, peroxidase, superoxide dismutase, and polyphenol oxidase (Çelik et al. 2009; Haghighat et al. 2014; Jalali et al. 2017; Lee et al. 2012; Li et al. 2013; Maffei 2014; Payez et al. 2013; Poinapen et al. 2013; Radhakrishnan et al. 2012b; Selim and El-Nady 2011; Trebbi et al. 2007). Similar to the PAL activity and phenolic compounds, the lignin contents were increased in the treated cells as a defense response (Fig. 1D). Lignin, as a defensive layer of plants, tightens the cell walls and plays a defensive role against ROS generation in plants in response to biotic and abiotic stresses (Morita et al. 2006). Consistently Abdolmaleki et al. (2007) reported that the lignin level in tobacco cells was significantly increased upon exposure to 10 and 30 mT SMFs.

Similar to the increase in total phenolics, our results demonstrated an increase in flavonoid, anthocyanin, and flavonol contents of the treated cells (Fig. 1C). Flavonoids are key components of the antioxidant system with such subgroups as flavonols and anthocyanins. They belong to a class of low molecular weight phenolic compounds with diverse range of functions (Falcone Ferreyra 2012). The trend of changes in the contents of flavonols and anthocyanins upon each treatment are different with each other possibly because of their parallel biosynthetic pathways from flavonoids. For example, the highest flavonol content was observed in the cells treated with SMF1 + MNP; while the highest amount of anthocyanins was measured in the cells treated with SMF2 + MNP. The other possible reason is because the oxidative processes degrade these compounds. Their induction by peroxide signaling on one hand and their oxidative degradation on the other hand caused different increments of these compounds compared to control upon different treatments (Khatami et al. 2020). This increase can also be attributed to different elicitation of their biosynthetic pathways, the enhanced enzymatic activity, and the expression of pertinent genes (Di Ferdinando et al. 2012). 
The increase in the PPO activity is a common physiological response upon exposure to oxidative stress. A similar observation was reported for hazel cell suspension cultures treated with the SMF and SMF combined with salicylic acid. Both treatments led to an increase in the PPO activity (Rezaei et al. 2010). This enzyme catalyzes the $\mathrm{O}_{2}$-dependent oxidation of phenolic compounds into highly reactive quinines. It plays a key role in lignin biosynthesis (Tahsili et al. 2014) and also in binding phenols to each other (Araji et al. 2014; Tahsili et al. 2014).

\subsection{Effect of the SMF and MNPs on the Phytochemical Compounds}

Phytochemical compounds are the main secondary metabolites with valuable pharmaceutical and medicinal properties (Dias et al. 2016). They play significant contributions on the antioxidant activity of plants. The phytochemical products of $D$. kotschyi cells were identified as apigenin, carvacrol, naringin, quercetin, rosmarinic acid, rutin, and thymol. The metabolism and accumulation of these phytochemical compounds can significantly be affected by different genetic and environmental factors (Golkar et al. 2019a). These metabolites significantly changed in cells and culture media of the elicited samples (Tables 1 and 2).

Thymol and carvacrol were shown nearly similar production patterns (Tables 1 and 2) because they are both monoterpenic phenol isomers, derived from the methyl erythritol phosphate (MEP) pathway (Majdi et al. 2017). The geranyl diphosphate as universal precursor of monoterpenes is synthesized by head-totail condensation of dimethylallyl diphosphate (DMADP) and isopentenyl diphosphate (IDP) as the final products of the MEP pathway. The difference between biosynthesis of thymol and carvacrolis is related to differences in the activity of cytochrome p450 family enzymes which are involved in the modification of terpinene to thymol and carvacrol. Consistent with other findings (Majdi et al. 2017), the biosynthesis of these products was shown to be up regulated by abiotic elicitors.

The rosmarinic acid is an important phenolic compound which is synthesized by phenylpropanoid pathway. Rosmarinic acid synthase catalyzes the transesterification reaction of 4-coumaroyl-CoA with 4hydroxyphenyllactic acid to rosmarinic acid (Petersen et al. 2009). The rosmaric acid production was induced consistent with the enhancement in the contents of MDA, total phenolics, lignin, flavanoids, and PAL activities that is possibly because of the similar biosynthetic steps. In general, the MNP were found more effective than the SMFs in inducing the rosmarinic acid biosynthesis.

Apigenin, naringin, quercetin, and rutin belong to the six major subclasses of flavonoids (Panche et al. 2016). The first step in the biosynthesis of flavonoids is catalyzed by chalcone synthase which led to the production of chalcones by the condensation of three molecules of malonyl-CoA and a single molecule of 4-coumaryl-CoA (Panche et al. 2016). The chalcone isomerase then closes the pyrone ring of chalcone and makes naringenin. A flavanone synthase enzyme oxidizes naringenin to apigenin. Quercetin is derived from naringenin through three consecutive steps catalyzed by naringenin 3-dioxygenase, flavonoid 3'-hydroxylase, and flavonol synthase. Rutin (quercetin-3-rhamnosyl glucoside) is synthesized from quercetin as a glycone, via the addition of a rhamnoside (glucose-rhamnose) by flavonoid-3-o- 
glucosyltransferase (Yang et al. 2008). The different contents of these phytochemicals under different treatments could possibly because of their competition in synthesis from the common intermediate molecules. The 4- coumaroyl-CoA, chalcone, and naringinin are used as primary intermediate molecules in the biosynthetic pathways of these compounds. Also, the type and intensity of treatments can affect on the activity and expression of genes of the specific enzymes in each compound biosynthesis, which ultimately leads to different elicitation responses.

In general, the contents of these phytochemicals were significantly different from one treatment to the other due to possible reasons including: (1) intracellular accumulation such as quercetin upon SMF1 treatment, (2) secretion into culture media such as rutin upon SMF2 + MNP treatment, (3) more biosynthetic yield such as rosmaric acid, (4) oxidative degradation, and (5) sensitivity to iron supplementation. Accordingly, further research is in high demand to scrutinize the physiological responses. All these products may protect plant cells against treatments with the SMFs and MNPs. A number of different biotic and abiotic stresses are capable of inducing the metabolism and accumulation of phytochemical compounds in plants (Dong et al. 2011; Peñuelas and Llusia 1997). These observations might be attributed to the effect of SMFs and MNPs on the structures and functions of cellular membranes. In addition, the cell membrane permeability is indirectly increased through disruption of the membrane integrity by the oxidative stress induction. It consequently disturbs normal transport processes across cell and leads to leakage of the phytochemicals into the culture media (Table 2). The higher lipid peroxidation of the treated cells is consistent with these observations (Fig. 1A). Similar observations were also reported for Viciafaba cells treated with 10-100 mT magnetic fields (Dhawi et al. 2009).

\section{Conclusion}

The elicitation effects of the MNPs on phenolic compounds and antioxidant activities in the suspensioncultured $D$. kotschyi cells were higher than that of the SMFs. The physiological responses of the cells exposed to the SMFs depend significantly on the magnetic field intensity and treatment duration. The cells experienced higher stress upon simultaneous treatment by the SMF and MNP. These physical and chemical abiotic elicitors activated the Shikimate pathway and enhanced phenolic and lignin contents. The phytochemical products (rosmarinic acid, naringin, thymol, carvacrol, apigenin, rutin, and quercetin) increased in the treated $D$. kotschyi cells and secreted to the culture media. These elicitors can be applied as a useful strategy in improving the synthesis of phytochemical products under controlled conditions.

\section{Declarations}

\section{Conflict of interest}

The authors declare that they have no conflict of interest.

\section{Funding}


This research did not receive any specific grant from funding agencies in the public, commercial, or nonprofit sectors.

\section{References}

Abdolmaleki P, Ghanati F, Sahebjamei H, Sarvestani AS (2007) Peroxidase activity, lignification and promotion of cell death in tobacco cells exposed to static magnetic field. The Environmentalist 27: 435440.

Ainsworth EA, Gillespie KM (2007) Estimation of total phenolic content and other oxidation substrates in plant tissues using Folin-Ciocalteu reagent. Nature Protocols 2(4): 875-877.

Akkol EK, Göger F, Koşar M, Başer KHC (2008) Phenolic composition and biological activities of Salvia halophila and Salvia virgata from Turkey. Food Chemistry 108, 942-949.

Aladjadjiyan A (2010) Influence of stationary magnetic field on lentil seeds. International Agrophysics 24(3): 321-324.

Araji S, Grammer TA, Gertzen R, Anderson SD, Mikulic-Petkovsek M, Veberic R, Phu ML, Solar A, Leslie CA, Dandekar AM (2014) Novel roles for the polyphenol oxidase enzyme in secondary metabolism and the regulation of cell death in walnut. Plant Physiology 164: 1191-1203.

Barreca D, Laganà G, Leuzzi U, Smeriglio A, Trombetta D, Bellocco E (2016) Evaluation of the nutraceutical, antioxidant and cytoprotective properties of ripe pistachio (Pistacia vera L. variety Bronte) hulls. Food Chemistry 196: 493-502.

Çelik Ö, Büyükuslu N, Atak Ç, Rzakoulieva A (2009) Effects of magnetic field on activity of superoxide dismutase and catalase in Glycine max L. Merr. roots. Polish Journal of Environmental Studies 18(2): 175-182.

Chandra S, Chakraborty N, Dasgupta A, Sarkar J, Panda K, Acharya K (2015) Chitosan nanoparticles: a positive modulator of innate immune responses in plants. Scientific Reports 5: 15195.

Coşkun Ş, Balabanlı B, Canseven A, Seyhan N (2009) Effects of continuous and intermittent magnetic fields on oxidative parameters in vivo. Neurochemical Research 34(2): 238-243.

Dhawi F, Al-Khayri JM, Hassan E (2009) Static magnetic field influence on elements composition in date palm (Phoenix dactylifera L.). Research Journal of Agriculture and Biological Sciences 5: 161-166.

Dhoke SK, Mahajan P, Kamble R, Khanna A (2013) Effect of nanoparticles suspension on the growth of mung (Vigna radiata) seedlings by foliar spray method. Nanotechnology Development 3: e1.

Di Ferdinando M, Brunetti C, Fini A, Tattini M (2012) Flavonoids as antioxidants in plants under abiotic stresses. Abiotic stress responses in plants New York: Springer p159-179. 
Dias MI, Sousa MJ, Alves RC, Ferreira IC (2016) Exploring plant tissue culture to improve the production of phenolic compounds: A review. Industrial Crops and Products 82: 9-22.

Dimkpa CO, McLean JE, Latta DE, Manangón E, Britt DW, Johnson WP, Boyanov MI, Anderson AJ (2012) $\mathrm{CuO}$ and $\mathrm{ZnO}$ nanoparticles: phytotoxicity, metal speciation, and induction of oxidative stress in sandgrown wheat. Journal of Nanoparticle Research 14: 1125.

Dixon RA, Paiva NL (1995) Stress-induced phenylpropanoid metabolism. The Plant Cell 7(7): 1085-1097.

Dong J, Ma X, Wei Q, Peng S, Zhang S (2011) Effects of growing location on the contents of secondary metabolites in the leaves of four selected superior clones of Eucommia ulmoides. Industrial Crops and Products 34: 1607-1614.

Falcone Ferreyra ML, Rius S, Casati P (2012) Flavonoids: biosynthesis, biological functions, and biotechnological applications. Frontiers in Plant Science 3: 222.

Fattahi M, Bonfill M, Fattahi B, Torras-Claveria L, Sefidkon F, Cusido RM, Palazon J (2016) Secondary metabolites profiling of Dracocephalum kotschyi Boiss at three phenological stages using uni-and multivariate methods. Journal of Applied Research on Medicinal and Aromatic Plants 3: 177-185.

Galland P, Pazur A (2005) Magnetoreception in plants. Journal of Plant Research 118: 371-389.

Gamborg O, Murashige T, Thorpe T, Vasil I (1976) Plant tissue culture media. In Vitro 12(7): 473-478.

Ghanati F, Abdolmaleki P, Vaezzadeh M, Rajabbeigi E, Yazdani M (2007) Application of magnetic field and iron in order to change medicinal products of Ocimum basilicum. The Environmentalist 27: 429-434.

Ghanati F, Morita A, Yokota H (2005) Effects of aluminum on the growth of tea plant and activation of antioxidant system. Plant and Soil 276: 133-141.

Golkar P, Taghizadeh M, Jalali SAH (2019a) Determination of phenolic compounds, antioxidant and anticancer activity of Chrozophora tinctoria accessions collected from different regions of Iran. Journal of food biochemistry 43(11): e13036.

Golkar P, Taghizadeh M, Noormohammadi A (2019b) Effects of sodium alginate elicitation on secondary metabolites and antioxidant activity of safflower genotypes under in vitro salinity stress. In Vitro Cellular and Developmental Biology-Plant 55(5): 527-538.

Golkar P, Taghizadeh M (2018) In vitro evaluation of phenolic and osmolite compounds, ionic content, and antioxidant activity in safflower (Carthamus tinctorius L.) under salinity stress. Plant Cell, Tissue, and Organ Culture 134: 357-368.

Haghighat N, Abdolmaleki P, Ghanati F, Behmanesh M, Payez A (2014) Modification of catalase and MAPK in Vicia faba cultivated in soil with high natural radioactivity and treated with a static magnetic 
field. Journal of Plant Physiology 171: 99-103.

Hara M, Oki K, Hoshino K, Kuboi T (2003) Enhancement of anthocyanin biosynthesis by sugar in radish (Raphanus sativus) hypocotyl. Plant Science 164: 259-265.

Heath RL, Packer L (1968) Photoperoxidation in isolated chloroplasts: I. Kinetics and stoichiometry of fatty acid peroxidation. Archives of Biochemistry and Biophysics 125: 189-198.

Heidarabadi MD, Ghanati F, Fujiwara T (2011) Interaction between boron and aluminum and their effects on phenolic metabolism of Linum usitatissimum L. roots. Plant Physiology and Biochemistry 49: 13771383.

liyama K, Wallis AF (1990) Determination of lignin in herbaceous plants by an improved acetyl bromide procedure. Journal of the Science of Food and Agriculture 51: 145-161.

Jalali M, Ghanati F, Modarres-Sanavi A, Khoshgoftarmanesh A (2017) Physiological effects of repeated foliar application of magnetite nanoparticles on maize plants. Journal of Agronomy and Crop Science 203: 593-602.

Jamshidi M, Ghanati F, Rezaei A, Bemani E (2016) Change of antioxidant enzymes activity of hazel (Corylus avellana L.) cells by AgNPs. Cytotechnology 68: 525-530.

Khatami F, Najafi F, Yari F, Khavari-Nejad RA (2020) Expression of etr1-1 gene in transgenic Rosa hybrida L. increased postharvest longevity through reduced ethylene biosynthesis and perception. Scientia Horticulturae 263: 109103.

Khvatkov P, Chernobrovkina M, Okuneva A, Shvedova A, Chaban I Dolgov S (2015) Callus induction and regeneration in Wolffia arrhiza (L.) Horkel ex Wimm. Plant Cell, Tissue, and Organ Culture 120: 263-273.

Lee W-M, Kwak JI, An Y-J (2012) Effect of silver nanoparticles in crop plants Phaseolus radiatus and Sorghum bicolor. media effect on phytotoxicity. Chemosphere 86: 491-499.

Li J, Chang PR, Huang J, Wang Y, Yuan H, Ren H (2013) Physiological effects of magnetic iron oxide nanoparticles towards watermelon. Journal of Nanoscience and Nanotechnology 13: 5561-5567.

Ma X, Geiser-Lee J, Deng Y, Kolmakov A (2010) Interactions between engineered nanoparticles (ENPs) and plants: phytotoxicity, uptake and accumulation. Science of The Total Environment 408: 3053-3061.

Maffei ME (2014) Magnetic field effects on plant growth, development, and evolution. Frontiers in Plant Science 5: 445.

Majdi M, Malekzadeh-Mashhady A, Maroufi A, Crocoll C (2017) Tissue-specific gene-expression patterns of genes associated with thymol/carvacrol biosynthesis in thyme (Thymus vulgaris $\mathrm{L}$.) and their 
differential changes upon treatment with abiotic elicitors. Plant Physiology and Biochemistry 115: 152162.

Manquián-Cerda K, Escudey M, Zúñiga G, Arancibia-Miranda N, Molina M, Cruces E (2016) Effect of cadmium on phenolic compounds, antioxidant enzyme activity and oxidative stress in blueberry (Vaccinium corymbosum L.) plantlets grown in vitro. Ecotoxicology and Environmental Safety 133: 316326.

Maqsood S, Benjakul S, Abushelaibi A, Alam A (2014) Phenolic compounds and plant phenolic extracts as natural antioxidants in prevention of lipid oxidation in seafood: a detailed review. Comprehensive Reviews in Food Science and Food Safety 13: 1125-1140.

Moghaddam G, Ebrahimi SA, Rahbar-Roshandel N, Foroumadi A (2012) Antiproliferative activity of flavonoids: influence of the sequential methoxylation state of the flavonoid structure. Phytotherapy Research 26: 1023-1028.

Morita A, Yokota H, Ishka MR, Ghanati F (2006) Changes in peroxidase activity and lignin content of cultured tea cells in response to excess manganese. Soil Science and Plant Nutrition 52: 26-31.

Nagy P, Fischl G (2004) Effect of static magnetic field on growth and sporulation of some plant pathogenic fungi. Bioelectromagnetics 25: 316-318.

Panche AN, Diwan AD, Chandra SR (2016) Flavonoids: An overview. Journal of Nutritional Science 5: 115.

Pandya SR, Singh M (2015) Dispersion and optical activities of newly synthesized magnetic nanoparticles with organic acids and dendrimers in DMSO studied with UV/vis spectrophotometry. Journal of Molecular Liquids 211: 146-156.

Payez A, Ghanati F, Behmanesh M, Abdolmaleki P, Hajnorouzi A, Rajabbeigi E (2013) Increase of seed germination, growth and membrane integrity of wheat seedlings by exposure to static and a $10-\mathrm{KHz}$ electromagnetic field. Electromagnetic Biology and Medicine 32: 417-429.

Peñuelas J, Llusià J (1997) Effects of carbon dioxide, water supply, and seasonality on terpene content and emission by Rosmarinus officinalis. Journal of Chemical Ecology 23: 979-993.

Petersen M, Abdullah Y, Benner J, Eberle D, Gehlen K, Hucherig S, Janiak V, Kim KH, Sander M, Weitzel C, Wolters S (2009) Evolution of rosmaric acid biosynthesis. Phytochemistry 70: 1663-1679.

Poinapen D, Toppozini L, Dies H, Brown DC, Rheinstädter MC (2013) Static magnetic fields enhance lipid order in native plant plasma membrane. Soft Matter 9: 6804-6813.

Radhakrishnan R, Kumari BDR (2012a) Pulsed magnetic field: a contemporary approach offers to enhance plant growth and yield of soybean. Plant Physiology and Biochemistry 51: 139-144. 
Radhakrishnan R, Leelapriya T, Kumari BDR (2012b) Effects of pulsed magnetic field treatment of soybean seeds on calli growth, cell damage, and biochemical changes under salt stress.

Bioelectromagnetics 33: 670-681.

Rajabbeigi E, Ghanati F, Abdolmaleki P, Payez A (2013) Antioxidant capacity of parsley cells (Petroselinum crispum L.) in relation to iron-induced ferritin levels and static magnetic field. Electromagnetic Biology and Medicine 32: 430-441.

Rezaei A, Ghanati F, Behmanesh M (2010) Static magnetic field improved salicylic acid effect on taxol production in suspension-cultured hazel (Corylus avellana) cells. $6^{\text {th }}$ International Workshop on Biological Effects of Electromagnetic Fields 70.

Safari M, Ghanati F, Behmanesh M, Hajnorouzi A, Nahidian B, Mina G (2013) Enhancement of antioxidant enzymes activity and expression of CAT and PAL genes in hazel (Corylus avellana L.) cells in response to low-intensity ultrasound. Acta Physiologiae Plantarum 35: 2847-2855.

Sahebjamei H, Abdolmaleki P, Ghanati F (2007) Effects of magnetic field on the antioxidant enzyme activities of suspension-cultured tobacco cells. Bioelectromagnetics 28: 42-47.

Salehi M, Hejazi SMH, Tabaei R (2015) Genetic differentiation of two Dracocephalum (Lamiaceae) species and populations in Iran by Polyacrylamide Gel Electrophoresis. Research Trend. 300.

Selim A-FH, El-Nady MF (2011) Physio-anatomical responses of drought stressed tomato plants to magnetic field. Acta Astronautica 69: 387-396.

Shang G-M, Wu J-C, Yuan Y-J (2004) Improved cell growth and Taxol production of suspension-cultured Taxus chinensis var. mairei in alternating and direct current magnetic fields. Biotechnology Letters 26: 875-878.

Shokrollahi S, Ghanati F, Sajedi RH, Sharifi M (2018) Possible role of iron containing proteins in physiological responses of soybean to static magnetic field. Journal of Plant Physiology 226: 163-171.

Tahsili J, Sharifi M, Safaie N, Esmaeilzadeh-Bahabadi S, Behmanesh M (2014) Induction of lignans and phenolic compounds in cell culture of Linum album by culture filtrate of Fusarium graminearum. Journal of Plant Interactions 9: 412-417.

Tenforde T (1996) Interaction of ELF magnetic fields with living systems. In: Polk C, Postow, E. (ed.) Biological effects of electromagnetic fields. Washington D.C.: CRC Press 185-230.

Trebbi G, Borghini F, Lazzarato L, Torrigiani P, Calzoni GL, Betti L (2007) Extremely low frequency weak magnetic fields enhance resistance of $\mathrm{NN}$ tobacco plants to tobacco mosaic virus and elicit stress-related biochemical activities. Bioelectromagnetics 28: 214-223. 
Wang H-Y, Zeng X-B, Guo S-Y, Li Z-T (2008) Effects of magnetic field on the antioxidant defense system of recirculation-cultured Chlorella vulgaris. Bioelectromagnetics 29: 39-46.

Wang JW, Zheng LP, Wu JY, Tan RX (2006) Involvement of nitric oxide in oxidative burst, phenylalanine ammonia-lyase activation and Taxol production induced by low-energy ultrasound in Taxus yunnanensis cell suspension cultures. Nitric Oxide 15: 351-358.

Yang J, Guo J, Yuan J (2008) In vitro antioxidant properties of rutin LWT-Food Science and Technology 41(6): 1060-1066.

Yue W, Ming Q-L, Lin B, Rahman K, Zheng C-J, Han T, Qin L-P (2016) Medicinal plant cell suspension cultures: pharmaceutical applications and high-yielding strategies for the desired secondary metabolites. Critical Reviews in Biotechnology 36: 215-232.

Zia-ur-Rehman M, Naeem A, Khalid H, Rizwan M, Ali S, Azhar M (2018) Responses of plants to iron oxide nanoparticles. Nanomaterials in plants, algae, and microorganisms 1: 221-238.

\section{Figures}
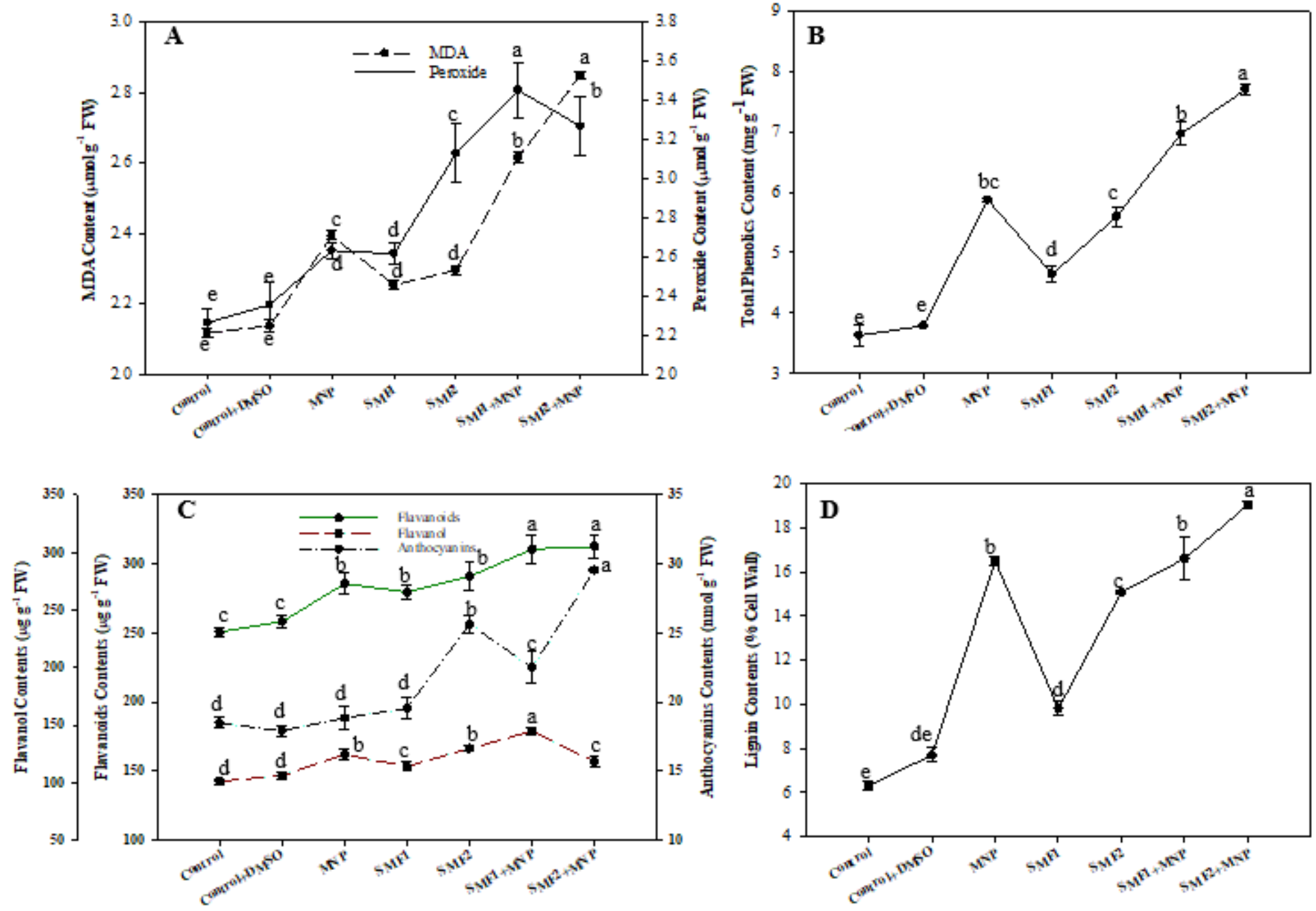


\section{Figure 1}

Effects of static magnetic field at $30 \mathrm{mT}, 100 \mathrm{ppm}$ MNP, and their combination on the contents of peroxides and MDA (A), total phenolics (B), flavonoids, flavonols, and anthocyanins (C), and lignin (D) in the suspension cultured D. kotschyi cells. MNP: Fe304 MNP; SMF1: Static magnetic field for 3 days, $3 \mathrm{~h}$ per day; SMF2: Static magnetic field for 4 days, $5 \mathrm{~h}$ per day; SMF1 + MNP: Static magnetic field for 3 days, $3 \mathrm{~h}$ per day with Fe304 MNP; and SMF2 + MNP: Static magnetic field for 4 days, $5 \mathrm{~h}$ per day with Fe304 MNP. Vertical bars indicate mean values \pm SE of three replicates. The mean values followed by the same letter are not significantly different at $\mathrm{P} \leq 0.05$ according to the Duncan's test.



Figure 2

Effects of static magnetic field at $30 \mathrm{mT}, 100 \mathrm{ppm}$ MNP, and their combination on the activities of PAL and PPO in the suspension cultured D. kotschyi cells. MNP: Fe304 magnetic nanoparticles, SMF1: Static magnetic field for 3 days, $3 \mathrm{~h}$ a day, SMF2: Static magnetic field for 4 days, $5 \mathrm{~h}$ a day, MNP+SMF1: Static magnetic field for 3 days, $3 \mathrm{~h}$ a day with Fe304 MNP, MNP+SMF2: Static magnetic field for 4 days, $5 \mathrm{~h}$ a day with Fe304 MNP. Vertical bars indicate means \pm SE of three replicates. Different lowercase letters show a significant difference at $\mathrm{P} \leq 0.05$ according to Duncan's test. 